\title{
AS DEMONSTRAÇÕES CONTÁBEIS COMO FERRAMENTA DE CREDIBILIDADE ÀS ENTIDADES RELIGIOSAS
}

\section{ARTIGO ORIGINAL}

LEAL, Asaph Cavalho ', CONCEIÇÃO, Thais Carla da 2, SANTANA FILHO, Ivan Emerson de ${ }^{3}$, ROBERTO, José Carlos Alves ${ }^{4}$, SERRA, Meg Rocha da Cunha ${ }^{5}$, LOPES, Nelânia Ferreira 6

LEAL, Asaph Cavalho. Et al. As demonstrações contábeis como ferramenta de credibilidade às entidades religiosas. Revista Científica Multidisciplinar Núcleo do Conhecimento. Ano. 06, Ed. 11, Vol. 03, pp. 179-204. Novembro 2021. ISSN: 24480959, Link de acesso: https://www.nucleodoconhecimento.com.br/contabilidade/entidadesreligiosas

${ }^{1}$ Graduando do curso de Contabilidade.

${ }^{2}$ Graduanda do curso de Contabilidade.

${ }^{3}$ Graduando do curso de contabilidade.

4 Orientador. Mestre em Engenharia de produção. Especialista Logística empresarial. Graduado em Administração com Ênfase em Marketing.

5 Orientadora. Mestra em Engenharia de Processos Industriais pela UFPA, especialista em Controladoria e Auditoria Contábil pelo Ciesa, Graduada em Ciências Contábeis pelo Centro Universitário do Norte. Graduada em Ciências Econômicas pelo Centro Universitário do Norte.

${ }^{6}$ Orientadora. Especialista em Auditoria Contábil, Financeira e Tributaria e Graduada em Ciências Contábeis.

RC: 100749

Disponível em: https://www.nucleodoconhecimento.com.br/contabilidade/entidades-religiosas 


\section{RESUMO}

O presente artigo busca demonstrar que o Terceiro Setor exerce um papel de destaque na sociedade brasileira. Esta pesquisa visa evidenciar como as demonstrações contábeis auxiliam as entidades religiosas a passar a devida credibilidade aos seus fiéis, aos seus doadores e à comunidade, com o objetivo de apresentar de forma transparente a relação de seus recursos recebidos e suas despesas, bem como constituir uma boa imagem e manter suas atividades em funcionamento. O Terceiro Setor manifesta-se no país devido à necessidade de auxiliar a sociedade nas atividades em que o Primeiro Setor não alcançou de forma eficiente no que diz respeito ao bem-estar social. Diante disto, surgiu a questão norteadora: de que maneira as demonstrações contábeis podem trazer credibilidade às entidades religiosas? Sem ter como finalidade o lucro, apenas colaborar de forma positiva em diversas áreas, como saúde, educação, lazer, direitos humanos, dentre outras, este setor ganha cada vez mais espaço por meio de ONGs, associações, fundações, instituições e igrejas e, com isso, essas instituições precisam estar devidamente regularizadas a partir dos órgãos competentes e manter a contabilidade atualizada para ter a capacidade de realizar tarefas vistas como positivas ao coletivo. O objetivo geral deste estudo é mostrar a transparência das demonstrações contábeis, as receitas advindas de doações, parcerias, ofertas, dízimos e patrocínios, assim como das despesas geradas. Quanto à metodologia, a presente pesquisa foi realizada por meio de um estudo de caráter bibliográfico. Esta pesquisa pretende fornecer informações necessárias no que diz respeito à importância das demonstrações contábeis nas entidades sem fins lucrativos, dando ênfase nas instituições religiosas, a fim de contribuir de forma assertiva perante a sociedade. O presente estudo possibilita o entendimento quanto ao funcionamento da contabilidade de instituições do Terceiro Setor, de suas demonstrações e de suas classificações legais.

Palavras-Chave: Terceiro Setor, Contabilidade, Organizações Religiosas.

RC: 100749

Disponível em: https://www.nucleodoconhecimento.com.br/contabilidade/entidades-religiosas 


\section{INTRODUÇÃO}

Terceiro Setor, expressão proveniente da língua inglesa (Third Sector), surge da necessidade de dar destaque à filantropia moderna, sendo constituído por instituições privadas que focam em questões sociais e coletivas sem buscar lucro. A importância do Terceiro Setor nasce das brechas e necessidades sociais causadas pelo enfraquecimento do Estado, entrando em contato com a ascensão do neoliberalismo e o desinteresse das instituições privadas com essas mazelas sociais (ALMEIDA; ESPEJO, 2012), sem intenção de substituir o Estado na sua função de cumpridor das políticas sociais, e sim, explorar suas fraquezas e crescer junto a elas. O objetivo geral deste estudo é discutir sobre a transparência das demonstrações contábeis, isto é, sobre as receitas advindas de doações, parcerias, ofertas, dízimos e patrocínios, assim como sobre as despesas geradas.

Esta pesquisa pretende levantar informações necessárias sobre a importância das demonstrações contábeis nas entidades sem fins lucrativos, dando ênfase nas instituições religiosas a fim de contribuir de forma assertiva com a sociedade, apresentando informações transparentes (BARBIERI, 2008). Como qualquer empresa em pleno funcionamento, existe a necessidade legal do cumprimento de suas obrigações fiscais, dentre elas prestação de suas Demonstrações Contábeis, exigidas para sua legalidade institucional. Existe também a necessidade de prestação de contas, accountability, processo este que gera a credibilidade indispensável para seu funcionamento, já que, em grande parte, subsiste com subvenções estatais, que demandam suspeição fiscal, e por meio de doações de seus fiéis, como é o caso das instituições religiosas.

Diante disto, tem como questão norteadora: de que maneira as demonstrações contábeis podem trazer credibilidade às entidades religiosas? Portanto, analisa-se de que forma as demonstrações devem ser executadas corretamente, trazendo fé pública para suas atividades. Parte-se de uma pesquisa bibliográfica e discorre-se

RC: 100749

Disponível em: https://www.nucleodoconhecimento.com.br/contabilidade/entidades-religiosas 
sobre como são realizadas as demonstrações contábeis para essas instituições, explicando como são constituídas as diversas instituições dessa classificação, destacando instituições religiosas. Esclarece-se, de forma descritiva, sobre quais são as demonstrações apresentadas e sua importância para as instituições, estabelecendo uma base para pesquisas futuras que deverão ser realizadas posteriormente. Expõe-se de forma clara as conceituações, explicando como devem ser realizadas e destacando a relação intrínseca entre os pontos a serem trabalhados.

\section{FUNDAMENTAÇÃO TEÓRICA}

\subsection{TERCEIRO SETOR}

O setor econômico do regime capitalista no Brasil é estruturado por um emaranhado de atividades, as quais culminam em uma enorme cadeia de produção de bens e serviços que se destina a suprir os anseios e as necessidades da sociedade em geral. Por conseguinte, Araújo (2009) aponta a existência de três setores distintos que possibilitam desenvolvimento de atividades sociais e econômicas, que são: $O$ Primeiro Setor ou Setor Público, Segundo Setor ou Setor Privado e Terceiro Setor. Basicamente, o Setor Público, ou o primeiro setor, é formado pelos órgãos que são de competência do Estado, ou seja, é produto da administração das verbas e bens públicos geridas pelos governos federais, estaduais e municipais. Em contraste com as características do Primeiro Setor, que visa ao atendimento das necessidades da sociedade, o Segundo Setor, ou Setor Privado, é constituído por empresas particulares, cujas atividades econômicas que exercem visam à obtenção de lucro, ganhos que culminam no enriquecimento próprio.

Já o Terceiro Setor, de maneira geral, é composto por organizações que não pertencem à esfera governamental e nem ao Setor Privado, porém França (2015) afirma que o Terceiro Setor é privado, contudo, público. O que se compreende a

RC: 100749

Disponível em: https://www.nucleodoconhecimento.com.br/contabilidade/entidades-religiosas 
partir dessa afirmativa é que este setor, oriundo da sociedade civil, não é, em sua totalidade, público e nem foge totalmente dos princípios que regem as empresas privadas. Desse modo, o Terceiro Setor é ajuizado por organizações privadas, porque são cadastradas juridicamente e são originadas por iniciativa particular, contudo, diferenciam-se das empresas do Segundo Setor, porque não visam lucratividade e se dedicam às ações com objetivos sociais ou públicos, mesmo não fazendo parte dos órgãos pertencentes ao governo (FRANÇA, 2015).Tais instituições caracterizam-se juridicamente como entidades que oferecem serviços em diversas áreas, como saúde, educação e defesa de direitos.

surgimento da apreciação do Terceiro Setor vislumbra as peculiaridades do próprio conceito, de suas finalidades, o caráter das suas intenções, de sua forma jurídica e as características que se atrelam à ação de obter subsídios para garantir a sua sobrevivência (COELHO, 2002). Rodrigues (2010), em relação ao que se caracteriza como Terceiro Setor, afirma que sindicatos, associações, igrejas, cooperativas ou quaisquer outras organizações nas quais não há existência de finalidades lucrativas, que não fazem distribuição de seus ganhos aos associados, que atuam independentemente do Setor Primário, são organizações pertencentes ao Terceiro Setor. De acordo com Paes (2010), o Terceiro Setor é o conjunto de organismos, organizações ou instituições sem fins lucrativos que possuem autonomia e administração própria, cuja função e objetivo principais são realizar serviços voluntários destinados à sociedade civil.

Isto também é definido pelo Código Civil, alterado pela Lei № 10.825, de 22 de dezembro de 2003, mencionando, como exemplos de instituições sem fins lucrativos, as associações, as sociedades, as fundações, as organizações religiosas e partidos políticos (incluídos pela lei 10.825/03) e as empresas individuais de responsabilidade limitada (incluída pela lei 12.441/01). 


\subsubsection{ASSOCIAÇÕES}

Uma das iniciativas mais comuns no setor terciário é composta pela criação de associações, que são as pessoas jurídicas, de direito privado, sem finalidade lucrativa, que se constituem a partir da união de indivíduos que apresentam objetivos comuns em prol de alguma causa. As associações são organizações que se baseiam em acordos que se estabelecem entre os indivíduos, com a finalidade de exercerem atividades comuns ou defenderem interesses comuns ou mútuos. As ações e objetivos dessas entidades voltam-se para fins pré-definidos pelos membros que delas fazem parte, o que engloba inúmeras variedades de objetivos e atividades, como recreativas, esportivas, culturais, artísticas, comunitárias e profissionais (OLAK; NASCIMENTO, 2010).

Já Cardoso (2014) esclarece que uma Associação é qualquer empreendimento, formal ou informal, que reúne pessoas físicas ou outras sociedades jurídicas com ideais em comum, objetivando oferecer serviços que superem dificuldades e que geram benefícios para os seus associados. Ou seja, uma associação é um método jurídico que atribui formas da lei às ações de pessoas que se uniram em prol de necessidades e objetivos comuns. Para que uma associação seja fundada, não existe a necessidade de já existir previamente algum patrimônio. Paes (2010), informa que a Lei de № 9790/79 abrange as entidades que constituem o Terceiro Setor e as define como todas e quaisquer que exibem, em seus regimentos, finalidades sociais, direcionando-se para o desenvolvimento de atividades voltadas para o interesse público.

Abarca-se diversas áreas que supram necessidades da sociedade, como, por exemplo, alimentação, saúde, habitação, cultura, educação, direitos humanos, defesa do meio ambiente etc. 


\subsubsection{FUNDAÇÕES}

As fundações são entidades criadas a partir da organização de um patrimônio com alguma finalidade ou objetivo pré-determinado, “(...)ou seja, nas fundações há um capital disponível para a realização dos objetivos, enquanto nas demais instituições há o objetivo em comum, porém muitas vezes ainda falta a fonte de recursos para a sua realização," como explica Andrade (2002, p. 37). Desse modo, compreende-se que a fundação é pessoa jurídica e de direito, que não possui fins lucrativos, voltada para causas sociais, mas que se compõe a partir da existência de patrimônio. Do Art. 62 ao 69, da Lei № 10.406/02 do código civil, aborda-se sobre normativas direcionadas às fundações, preconizando que elas devem existir somente para fins morais, culturais e ou assistencialistas.

Elas podem ser fundadas de duas maneiras: a primeira por atos intervivos, isto é, por duas pessoas ou mais em vida, por meio de Escritura Pública; e a segunda, por mortis causa, utilizando-se o testamento deixado. Em qualquer dos casos, faz-se necessária a presença do Ministério Público. Ainda, para que se constitua uma fundação, é necessário reserva de bens e patrimônios, tais como: propriedades, créditos ou dinheiro, legalmente disponíveis, a recomendação da finalidade legal, com suas especificações para que se destinará, e a forma de administração (ARAÚJO; CARRENHO, 2009). Em suma, o Terceiro Setor é formado por associações e por fundações, contudo, existem entidades que se enquadram nele a partir de títulos, certificações e qualificações, como pode ser exemplificado pelas instituições de Organizações Sociais (OS), Organizações da Sociedade Civil de Interesse Público (OSCIP), Organização Religiosa, dentre outras.

\subsubsection{ORGANIZAÇÕES SOCIAIS (OS)}

A partir da Lei № 9.790/99 e do Art. 86 da Lei Federal 13.019/14, compreende-se que Organização social é toda união de pessoas que compartilham ideais em

RC: 100749

Disponível em: https://www.nucleodoconhecimento.com.br/contabilidade/entidades-religiosas 
comum e que estejam de igual acordo, empenhados a trabalhar em prol dos mesmos objetivos, sendo eles com intenções solidárias ou particulares, como pode ser observado em alguns dos Artigos da Lei № 9.790/99:

Art. $1^{\circ}$ O Poder Executivo poderá qualificar como organizações sociais pessoas jurídicas de direito privado, sem fins lucrativos, cujas atividades sejam dirigidas ao ensino, à pesquisa científica, ao desenvolvimento tecnológico, à proteção e preservação do meio ambiente, à cultura e à saúde, atendidos aos requisitos previstos nesta Lei.

Art. $2^{\circ}$ São requisitos específicos para que as entidades privadas referidas no artigo anterior se habilitem à qualificação como organização social: a comprovação do seu ato constitutivo descrevendo a sua natureza social e área de atuação; comprovar a finalidade não-lucrativa e intenção de reinvestir seus superávits no desenvolvimento da atividade; previsão expressa do conselho administrativo e diretoria definida em estatuto conforme disposição legal (BRASIL, 1999).

\subsubsection{ORGANIZAÇÃO DA SOCIEDADE CIVIL DE INTERESSE PÚBLICO (OSCIP)}

Para tentar entender a definição de Organização da Sociedade Civil de Interesse Público (OSCIP), existe a necessidade de observar a sua regulamentação, que é fundada a começar pela Lei № 9.790, de 23 de março de 1999:

Art. 10 Podem qualificar-se como Organizações da Sociedade Civil de Interesse Público as pessoas jurídicas de direito privado, sem fins lucrativos, desde que os respectivos objetivos sociais e normas estatutárias atendam aos requisitos instituídos por esta Lei.

$\S 1^{\circ}$ Para os efeitos desta Lei, considera-se sem fins lucrativos a pessoa jurídica de direito privado que não distribui, entre os seus sócios ou associados, conselheiros, diretores, empregados ou doadores, eventuais excedentes operacionais, brutos ou líquidos, dividendos, bonificações, participações ou parcelas do seu patrimônio, auferidos mediante o exercício de suas atividades, e que os aplica integralmente na consecução do respectivo objeto social.

RC: 100749

Disponível em: https://www.nucleodoconhecimento.com.br/contabilidade/entidades-religiosas 
$\S 2^{\circ} \mathrm{A}$ outorga da qualificação prevista neste artigo é ato vinculado ao cumprimento dos requisitos instituídos por esta Lei (BRASIL, 1999).

\subsection{DEFINIÇÃO DE ORGANIZAÇÃO RELIGIOSA}

Conforme Olak e Nascimento (2010), pode-se mencionar que as instituições religiosas podem ser caracterizadas como instituições qualificadas como filantrópicas, beneficentes e de caridade. Em virtude de tais características, são criadas com o intuito de atender a sua clientela, ofertando, para que tal função seja cumprida, os trabalhos de assistência social (abrigos, orfanatos, centros para indigentes, distribuição de roupa e comida etc.) e de serviço sociais nos campos da saúde e da educação (colégios religiosos, universidades e hospitais religiosos). As organizações estão incluídas na categoria de fundação, sendo entidades filantrópicas empresariais, bem como classificadas como Associações pelo Código Civil Brasileiro. Os seus valores intrínsecos são o altruísmo, boa vontade e serviço à comunidade, valores esses que as diferenciam das demais associações.

Monello (2014), complementa que as organizações religiosas são instituídas envoltas em um manto confessional. Isto quer dizer que são empoderadas de direitos próprios, os quais regulam e disciplinam sua existência, organização e atividades. Fazem parte do tipo de organização descrita: Dioceses, Igrejas, Prelazias, Ordens, Mitras, Congregações, Institutos de Vida Apostólica, Institutos de Vida Consagrada, dentre outras. A falta de legislação que normatize as instituições faz com que essas organizações utilizem as leis direcionadas às organizações sem finalidades lucrativas quando precisam cumprir a escrituração contábil. O Conselho Federal de Contabilidade (CFC) emitiu a resolução CFC № 1.409/2012, que aprovou a Interpretação Técnica Geral (ITG) 2002, a qual determina quais os critérios de avaliação dos trâmites patrimoniais e de elaboração dos esclarecimentos contábeis. Por conta da falta de legislação e da autorização do ITG, as entidades religiosas enfrentam, atualmente, dificuldades para desempenhar obrigações fiscais.

RC: 100749

Disponível em: https://www.nucleodoconhecimento.com.br/contabilidade/entidades-religiosas 


\subsubsection{GESTÃO DA ENTIDADE RELIGIOSA}

Câmara e Kessler (2012, p. 13), em relação à gestão de uma entidade religiosa, conceituam que a Administração Eclesiástica é o estudo dos variados conteúdos ligados à atividade do pastor no que tange à sua função de líder ou administrador frente à igreja. É importante lembrar de que a igreja é considerada, ao mesmo tempo, organismo e organização. É o povo de Deus organizado num tríplice aspecto: espiritual, social e econômico que tem como objetivo atender à missão para qual Deus a constituiu. Gerir uma instituição religiosa vai muito além das atribuições ensinar a Bíblia, orar e aconselhar as pessoas. Segundo os próprios Câmara e Kessler (2012, p. 3): "Pastorear é muito mais que presidir. É administrar com eficiência os negócios do Reino de Deus".

$\mathrm{O}$ ato de liderar uma igreja requer planejamento, organização, delegação de funções, controle e acompanhamento das atribuições desempenhadas, controle da administração de recursos, dentre outras inerentes ao gerenciamento. As organizações religiosas possuem seus objetivos e metas estabelecidos e também se preocupam em realizar as suas atividades conforme sua missão, visão etc., como, por exemplo, o ensino da palavra para edificação da igreja, adoração a Deus e evangelismo. Para tanto, necessita, também, elaborar estratégias para que consiga subsidiar todos os custos para seu funcionamento, os quais podem ser exemplificados por todas as responsabilidades de custeio, como água, luz e os recursos humanos.

\subsubsection{TIPOS DE RECEITA}

Com o objetivo de manter suas atividades, é de extrema importância que as organizações que compõem o Terceiro Setor obtenham formas distintas de receitas, visto que suas atividades não têm como finalidade o lucro. Os tipos de receitas podem ocorrer por meio, também, de dízimos, patrocínios, auxílios, ofertas, 
doações e através dos setores municipal, estadual e federal, sendo essas últimas por meio de subvenções sociais. As subvenções sociais são concedidas às entidades sem fins lucrativos que prestarem serviços essenciais de assistência social, médica e educacional, de forma suplementar aos recursos de origem privada (MONTEIRO, 2011). Essa garantia constitucional proíbe aos poderes tributários, como a União, Estados ou Municípios, a cobrança de impostos sobre determinadas entidades, pessoas ou até mesmo situações específicas (OLIVEIRA; ROMÃO, 2011). As entidades religiosas têm algumas peculiaridades no que compete à titulação das contas como: a conta capital, integrante do balanço patrimonial (BP) deve ser substituída pela denominação de patrimônio social e as palavras lucro ou prejuízo devem ser substituídas por superávit ou déficit do período, de acordo com a Interpretação Técnica geral (CFC, 2002).

Quadro 01 - Relatório financeiro de receitas de entidades religiosas

\begin{tabular}{|l|l|}
\hline Descriminação & Valores R\$ \\
\hline Receitas Ordinárias & $\mathbf{1 . 8 0 0 . 0 0 0 , 0 0}$ \\
\hline Dízimos & $1.300,000,00$ \\
\hline Ofertas & $500.000,00$ \\
\hline Receitas Extraordinárias & $\mathbf{7 8 0 . 0 0 0 , 0 0}$ \\
\hline Imobilizado & $780.000,00$ \\
\hline Ministério de integração/ação social & $\mathbf{6 9 0 . 0 0 0 , 0 0}$ \\
\hline Contribuição e doações & $690.000,00$ \\
\hline Outras receitas & $\mathbf{3 3 0 . 0 0 0 , 0 0}$ \\
\hline Missão dos membros & $330.000,00$ \\
\hline Total de Receitas & $\mathbf{3 . 6 0 0 . 0 0 0 , 0 0}$ \\
\hline
\end{tabular}

Fonte: Elaborado pelos autores (2021) 


\subsubsection{TIPOS DE DESPESAS}

Assim como as outras organizações, as organizações religiosas também possuem obrigações sociais em razão da sua atuação na sociedade. Despesas como água, energia, ornamentos, bens de pequeno valor, dentre outros gastos são fundamentais para a manutenção do templo, a fim de atribuir o mínimo de estrutura e conforto para os fiéis ao longo do culto (NASCIMENTO JUNIOR, 2019). Para que não haja comprometimento das finanças das Organizações Religiosas, todo e qualquer tipo de despesa precisa ser registrado corretamente, respeitando o princípio da competência. Desta forma, para que o registro dessas despesas possa ser feito corretamente, Nascimento Junior (2019) sugere a elaboração de um formulário de saída revestido com formalidades extrínsecas e intrínsecas que o transformam em um documento comprobatório sobre esses fatores econômicos.

Trata-se, portanto, de um documento que irá gerar um fluxo de processos financeiros e abrangerá todo o ciclo organizacional de documentos, livros e outras peças internas e/ou externas que fundamentam a organização nos âmbitos jurídico, fiscal e contábil. Dessa forma, ainda que as organizações necessitem manter escrituração contábil, não existem hoje, no Brasil, normas exclusivas de contabilidade direcionadas às entidades religiosas, elas se utilizam da legislação vigente para as entidades sem finalidade de lucros. No entanto, essas organizações estão introduzidas no setor terciário e são privilegiadas com imunidade constitucional e, a fim de que permaneça com a imunidade, precisam escriturar suas receitas e despesas (SANTOS et al., 2019).

Quadro 02 - Relatório financeiro de despesas de entidades religiosas

\begin{tabular}{|l|l|}
\hline Descriminação & Valores $\mathrm{R} \$$ \\
\hline Despesas fixas & $\mathbf{9 9 0 . 0 0 0 , 0 0}$ \\
\hline Salários e encargos & $580.000,00$ \\
\hline
\end{tabular}

RC: 100749

Disponível em: https://www.nucleodoconhecimento.com.br/contabilidade/entidades-religiosas 


\begin{tabular}{|l|l|}
\hline Aluguel & $410.000,00$ \\
\hline Despesas Variáveis & $\mathbf{7 7 5 . 0 0 0 , 0 0}$ \\
\hline Energia & $190.000,00$ \\
\hline Água & $33.000,00$ \\
\hline Telefone internet & $22.000,00$ \\
\hline Alimentação & $55.000,00$ \\
\hline Material de expediente & $60.000,00$ \\
\hline Material de higiene e limpeza & $65.000,00$ \\
\hline Manutenção predial & $230.000,00$ \\
\hline Combustível & $120.000,00$ \\
\hline Despesas Financeiras & $\mathbf{4 4 . 0 0 0 , 0 0}$ \\
\hline Despesas bancárias & $44.000,00$ \\
\hline Total de Despesas & $\mathbf{1 . 8 0 9 . 0 0 0 , 0 0}$ \\
\hline
\end{tabular}

Fonte: Elaborado pelos autores (2021)

\subsection{TRIBUTAÇÃO NO TERCEIRO SETOR}

A Constituição Federal (1988) veda à União e aos Estados e Municípios a possibilidade de aplicar impostos sobre entidades de Terceiro Setor, como genericamente definimos. São elas as fundações, instituições de educação e assistência social que atendem as qualificações legislativas, além dos templos religiosos de qualquer culto e entidades sindicais. Esse trato diferenciado leva em consideração a função social de instituições de assistencialismo que preenchem as lacunas deixadas pelas limitações do Estado. Essas mesmas limitações ínsitas, como defende Souza (2004, p. 137), tornam as Entidades Sem Fins Lucrativos essenciais para os planejamentos desenvolvimentistas de suas respectivas esferas. 


\subsubsection{IMUNIDADE}

Essa impossibilidade sob uma exigência tributária é tecnicamente tratada como imunidade. A imunidade surge quando a constituição protege a oneração em uma condição pré-definida que, sem essa intercessão, o quadro seria naturalmente compreendido como tributável (BRITO; SEGUNDO, 2018). É importante definir a imunidade assim, constitucional, de legislação primária, sendo assim um componente essencial para as intenções de desenvolvimento de uma nação (SOUZA, 2004), além de representar a materialização do artigo quinto da constituição federal representados na liberdade de pensamento e religião (PAULSEN, 2020) e qualquer lei proposta para forçar a coleta de tributos de instituições dessa matéria torna-se, de imediato, anticonstitucional.

Destaquemos também, diante do contexto apresentado, que existem condições exigidas para a constituição de uma entidade de terceiro setor. Não basta compor seu contrato social afirmando não ter fins lucrativos, é necessário que essas instituições, embora possam negociar e gerar lucro para balancear suas finanças, respeitem o Art. 14 do Código Tributário Nacional - CTN e mantenham suas receitas registradas, reinvestem seus excedentes no aprimoramento da atividade fim e, mais importante de tudo, não repartam lucros entre os seus executivos e, também, stakeholders (OLAK; NASCIMENTO, 2010).

\subsubsection{ISENÇÃO}

A isenção, por sua vez, atua de outra forma em relação à imunidade, além disso, conforme já discutido, é constitucional e irrevogável para setores específicos da sociedade. Isenção tem natureza supressiva e concessória e, muitas vezes, responde à capacidade de pagamento e às características individuais de cada pagador, podendo, por vezes, desobrigar o encargo que o seria normalmente creditado e o tem como maior amostra o Imposto de Renda, que é calculado a partir

RC: 100749

Disponível em: https://www.nucleodoconhecimento.com.br/contabilidade/entidades-religiosas 
da renda do contribuinte e diversas especificações da sua realidade, imposto esse que pode ser desculpado, desobrigado, em síntese, isentado pela União (BRITO; SEGUNDO, 2018).

Exemplo esse traz clareza à natureza da isenção, embora não trate de entidades de terceiro setor, essas constitucionalmente imunes à exigência do Imposto de Renda de Pessoa Jurídica, ainda que, como definido no Art. 175 do CTN (BRASIL, 2012), essa imunidade não suspenda as suas obrigações acessórias e a improficiência em seu pagamento resultará em multa. Apesar de distintas devido seus regimentos substanciais, as premissas para efetivação da qualidade de isenção são as mesmas citadas quanto à imunidade e devem ser obrigatoriamente cumpridas para sua aplicação. Importante destacar, também, que a isenção existe quanto aos tributos direcionados ao lucro, como o Imposto de Renda, Contribuição Social sobre Lucro Líquido e ganhos de capitais sob investimento (PÊGAS, 2019).

\subsection{CONTABILIDADE APLICADA PARA O TERCEIRO SETOR}

Até o dia 23 de março de 1999, dia da promulgação da lei № 9.790 quanto à qualificação dos setores privados de interesses público, não existia legislação específica de trato às instituições sem fins lucrativos, o que as forçavam a utilizar a lei $N^{\circ}$ 6.404, relativa às Sociedades Anônimas. Isso forçava aos contadores uma flexibilidade, elaborando seus demonstrativos com base em legislação voltada para outro gênero, divergindo de sua natureza de não obtenção de lucro, sem seus regimes especiais para subvenções e doações, essenciais para as prestações de contas (FRANÇA, 2015).

Nesse sentido, destaca-se que a prestação de contas, realizada por meio de demonstrações contábeis definidas pela ITG - 2002 (Interpretação Técnica Geral,) assim como cada tipo de demonstração guiada pela sua própria norma, corresponde à forma pela qual as instituições sem fins lucrativos são admitidas em sua condição

RC: 100749

Disponível em: https://www.nucleodoconhecimento.com.br/contabilidade/entidades-religiosas 
fiscal, o que implica o atendimento a alguns requisitos fundamentais. Ainda que possuam imunidade garantida, é por meio da prestação de contas que demonstram estar adequados às normas, certificando sua validade e outorgando seu amparo (OLAK; NASCIMENTO, 2010).

\subsubsection{NORMAS BRASILEIRAS DE CONTABILIDADE (NBC T10)}

No fim do século $X X$, início do século $X X I$, ocorreram uma série de modificações no aparato em que as instituições de Terceiro Setor estavam envolvidas. A NBC, ou Norma Brasileira de Contabilidade, T10, foi criada nos anos 90 para padronizar as demonstrações contábeis de um setor que sobrevivia a base das interpretações de normas de escrituração para outros modelos de entidades (FRANÇA, 2015).

Foram essas modificações que permitiram a maior transparência, junto ao crescimento das entidades de Terceiro Setor pós redemocratização e promulgação da constituição, o que assegurou sua existência (THIESENA, 2009). Ao longo do tempo, artigos da NBC T10 foram atualizados e revogados, mas, a partir dessas modernizações, como, por exemplo, a promulgação da NBC T19.4, que tratava das doações e subvenções e fez com que as instituições nacionais estivessem a par com as normas internacionais que levariam, consequentemente, à publicação da Interpretação Técnica Geral - ITG 2002. Configuram um marcado importante, pois modernizaram ainda mais os processos junto às normas internacionais (FRANÇA, 2015).

\subsection{PRINCIPAIS DEMONSTRAÇÕES CONTÁBEIS DAS ENTIDADES RELIGIOSAS}

Diante do cenário aqui exposto, pode-se definir as demonstrações contábeis como a principal forma de interpretar o estado atual da entidade. Em virtude de tais características por elas assumidas, é um dever quanto ao fisco, sendo assim, são

RC: 100749

Disponível em: https://www.nucleodoconhecimento.com.br/contabilidade/entidades-religiosas 
instrumentos essenciais, desde que preservada a devida qualidade em seu processo de elaboração para melhor compreensão do fisco, administrativo e stakeholders (MONTOTO, 2018). Segundo a ITG 2002 (R1) e NBC TG 26, que preveem quais demonstrações serão exigidas nas instituições de fins lucrativos, são elas: Balanço Patrimonial, Demonstração de Superávit e Déficit do Exercício, Demonstração das Mutações do Patrimônio Líquido, Demonstrações de Fluxo de Caixa e Notas Explicativas.

Segundo o CRC-RS, em seu guia de orientação para o profissional da Contabilidade, no Terceiro Setor (2018) as demonstrações contábeis completas são compostas de balanço patrimonial, demonstração do resultado, demonstração do resultado abrangente, demonstração das mutações do patrimônio líquido, demonstrações do fluxo de caixa, demonstração do valor adicionado e notas explicativas. As demonstrações contábeis devem ser desenvolvidas respeitando as práticas contábeis empregadas no Brasil. Ao elaborar as demonstrações contábeis das organizações sem fins lucrativos, deve-se obedecer a Lei № 6.464/1976 e suas alterações, inseridas pela Lei № 11.638-2007 e Lei № 11.941-2009, que modificaram artigos inerentes à composição e à exposição das demonstrações contábeis.

\subsubsection{BALANÇO PATRIMONIAL}

O Balanço Patrimonial é a exposição clara e organizada dos registros contábeis escriturados de forma clara e legível para seus utilizadores. Padoveze (2010), define - Balanço Patrimonial como a mais importante demonstração, justamente pela leitura instintiva que separa as contas entre ativos e passivos, destacando pontos importantes, como o grau de liquidez dos elementos patrimoniais e seus bens, além de destacar suas obrigações a curto e longo prazo e os valores investidos por seus acionistas. As contas presentes em um Balanço Patrimonial de instituição sem fim lucrativo são, em geral, as mesmas que as empresas do Segundo Setor possuem,

RC: 100749

Disponível em: https://www.nucleodoconhecimento.com.br/contabilidade/entidades-religiosas 
tendo em vista a ampla utilização da Lei de S/A (OLAK, 2010), mas também leva em consideração as alterações feitas pela NBC T 10.19, o que, por sua vez, requer atenção da NBC T 3, solicitando a troca do nome da conta Capital Social para Patrimônio Social.

Quadro 03 - Modelo de Balanço Patrimonial das Entidades Religiosas

\begin{tabular}{|c|c|c|c|c|c|}
\hline & $\begin{array}{l}31 / 12 / 20 \\
13\end{array}$ & $\begin{array}{l}31 / 12 / 20 \\
12\end{array}$ & & $\begin{array}{l}31 / 12 / 201 \\
3\end{array}$ & $\begin{array}{l}31 / 12 / 201 \\
2\end{array}$ \\
\hline ATIVO & & & $\begin{array}{l}\text { PASSIVO } \\
\text { PATRIMÔNIO } \\
\text { LÍQUIDO }\end{array}$ & & \\
\hline CIRCULANTE & $\begin{array}{l}128.963, \\
72\end{array}$ & $\begin{array}{l}\text { 116.211, } \\
79\end{array}$ & CIRCULANTE & $87.074,27$ & $73.243,16$ \\
\hline DISPONÍVEL & & & EXIGÍVEL & & \\
\hline CAIXA & $\begin{array}{l}21.460,4 \\
8\end{array}$ & $\begin{array}{l}13.421,8 \\
3\end{array}$ & $\begin{array}{l}\text { FORNECEDOR } \\
\text { ES }\end{array}$ & $5.426,08$ & \\
\hline $\begin{array}{l}\text { BANCO } \\
\text { CONTA } \\
\text { MOVIMENTO }\end{array}$ & & & $\begin{array}{l}\text { OBRIGAÇÕES } \\
\text { TRABALHISTAS }\end{array}$ & & \\
\hline $\begin{array}{l}\text { BANCO DO } \\
\text { BRASIL }\end{array}$ & $\begin{array}{l}101.113, \\
24\end{array}$ & $\begin{array}{l}100.289, \\
38\end{array}$ & $\begin{array}{l}\text { SALÁRIOS A } \\
\text { PAGAR }\end{array}$ & $14.957,66$ & $13.938,66$ \\
\hline & & & $\begin{array}{l}\text { FÉRIAS } \\
\text { PAGAR }\end{array}$ & 74,28 & \\
\hline $\begin{array}{l}\text { ADTO DE } \\
\text { FORNECEDO } \\
\text { RES }\end{array}$ & & & & & \\
\hline ADTO & $6.390,00$ & & OBRIGAÇÕES & & \\
\hline
\end{tabular}

RC: 100749

Disponível em: https://www.nucleodoconhecimento.com.br/contabilidade/entidades-religiosas 


\begin{tabular}{|c|c|c|c|c|c|}
\hline $\begin{array}{l}\text { SERVIÇOS } \\
\text { PRESTADOS }\end{array}$ & & & SOCIAIS & & \\
\hline & & & INSS A PAGAR & $11.528,13$ & $9.867,84$ \\
\hline $\begin{array}{l}\text { CRÉDITO A } \\
\text { FUNCIONÁRI } \\
\text { OS }\end{array}$ & & & IRRF A PAGAR & $3.693,61$ & $2.980,75$ \\
\hline $\begin{array}{l}\text { ADTO A } \\
\text { FUNCIONÁRI } \\
0\end{array}$ & & $2.500,58$ & FGTS A PAGAR & $2.305,26$ & $2.284,11$ \\
\hline $\begin{array}{l}\text { NÃO } \\
\text { CIRCULANTE }\end{array}$ & $\begin{array}{l}223.824, \\
18\end{array}$ & $\begin{array}{l}273.096, \\
38\end{array}$ & $\begin{array}{l}\text { OBRIGAÇÕES } \\
\text { TRIBUTÁRIAS }\end{array}$ & & \\
\hline IMOBILIZADO & & & PIS A PAGAR & 288,16 & 194,01 \\
\hline $\begin{array}{l}\text { INSTALAÇÕE } \\
\text { S }\end{array}$ & $\begin{array}{l}26.217,2 \\
4\end{array}$ & $\begin{array}{l}21.430,2 \\
4\end{array}$ & $\begin{array}{l}\text { RETENÇÃO S/ } \\
\text { TOMADOR }\end{array}$ & 387,21 & 191,02 \\
\hline VEÍCULOS & $\begin{array}{l}57.449,3 \\
0\end{array}$ & $\begin{array}{l}57.449,3 \\
0\end{array}$ & & & \\
\hline $\begin{array}{l}\text { MÁQUINAS E } \\
\text { EQUIPAMENT } \\
\text { OS }\end{array}$ & $\begin{array}{l}497.502, \\
43\end{array}$ & $\begin{array}{l}487.812, \\
58\end{array}$ & PROVISÕES & & \\
\hline $\begin{array}{l}\text { MOVEIS E } \\
\text { UTENSÍLIOS }\end{array}$ & $\begin{array}{l}151.031 \\
67\end{array}$ & $\begin{array}{l}151.031, \\
67\end{array}$ & $\begin{array}{l}\text { PROVISÕES } \\
\text { FÉRIAS }\end{array}$ & $35.650,90$ & $32.243,63$ \\
\hline $\begin{array}{l}\text { EMBARCAÇÕ } \\
\text { ES }\end{array}$ & $\begin{array}{l}700.353 \\
04\end{array}$ & $\begin{array}{l}700.353, \\
04\end{array}$ & $\begin{array}{l}\text { PROVISÕES } \\
\text { INSS S/ FÉRIAS }\end{array}$ & $9.554,44$ & $8.641,27$ \\
\hline COMPUTADO & $4.499,45$ & $4.499,45$ & PROVISÕES & $2.852,04$ & $2.579,45$ \\
\hline $\begin{array}{l}\text { RES E } \\
\text { PERIFÉRICO } \\
S\end{array}$ & & & $\begin{array}{l}\text { FGTS } \\
\text { FÉRIAS }\end{array}$ & & \\
\hline
\end{tabular}




\begin{tabular}{|c|c|c|c|c|c|}
\hline \multirow[b]{2}{*}{$\begin{array}{l}\text { DEPRECIAÇÃ } \\
\text { O }\end{array}$} & & & $\begin{array}{l}\text { PROVISÃO PIS } \\
\text { S/ FÉRIAS }\end{array}$ & 356,50 & 322,42 \\
\hline & & & & & \\
\hline $\begin{array}{l}\text { INSTALAÇÕE } \\
\text { S }\end{array}$ & $\begin{array}{l}(16.445,8 \\
9)\end{array}$ & $\begin{array}{l}(13.899,9 \\
2)\end{array}$ & $\begin{array}{l}\text { PATRIMÔNIO } \\
\text { LÍQUIDO }\end{array}$ & $\begin{array}{l}265.713,6 \\
3\end{array}$ & $\begin{array}{l}316.065,0 \\
1\end{array}$ \\
\hline VEÍCULOS & $\begin{array}{l}(57.449,3 \\
0)\end{array}$ & $\begin{array}{l}(57.449,3 \\
0)\end{array}$ & $\begin{array}{l}\text { RESULTADO } \\
\text { SOCIAL }\end{array}$ & & \\
\hline $\begin{array}{l}\text { MÁQUINAS E } \\
\text { EQUIPAMENT } \\
\text { OS }\end{array}$ & $\begin{array}{l}(325.032, \\
55)\end{array}$ & $\begin{array}{l}(278.932, \\
67)\end{array}$ & $\begin{array}{l}\text { SUPERÁVIT/DÉ } \\
\text { FICIT }\end{array}$ & & \\
\hline $\begin{array}{l}\text { MOVEIS E } \\
\text { UTENSÍLIOS }\end{array}$ & $\begin{array}{l}(109.448, \\
72)\end{array}$ & $\begin{array}{l}(94.345,5 \\
2)\end{array}$ & $\begin{array}{l}\text { RESULTADO } \\
\text { POSITIVO } \\
\text { ACUMULADO }\end{array}$ & $\begin{array}{l}1.060 .605 \\
, 93\end{array}$ & $\begin{array}{l}1.060 .605 \\
, 93\end{array}$ \\
\hline $\begin{array}{l}\text { EMBARCAÇÕ } \\
\text { ES }\end{array}$ & $\begin{array}{l}(700.353 \\
04)\end{array}$ & $\begin{array}{l}(700.353, \\
04)\end{array}$ & $\begin{array}{l}\text { RESULTADO } \\
\text { NEGATIVO } \\
\text { ACUMULADO }\end{array}$ & $\begin{array}{l}(794.892, \\
30)\end{array}$ & $\begin{array}{l}(744.540, \\
92)\end{array}$ \\
\hline $\begin{array}{l}\text { COMPUTADO } \\
\text { RES } \\
\text { PERIFÉRICO } \\
S\end{array}$ & $\begin{array}{l}(4.499,45 \\
)\end{array}$ & $\begin{array}{l}(4.499,45 \\
)\end{array}$ & & & \\
\hline TOTAL & $\begin{array}{l}352.787 \\
90\end{array}$ & $\begin{array}{l}389.308 \\
17\end{array}$ & TOTAL & $\begin{array}{l}352.787,9 \\
0\end{array}$ & $\begin{array}{l}389.308,1 \\
7\end{array}$ \\
\hline
\end{tabular}

Fonte: Elaborado pelos autores (2021) 


\subsubsection{DEMONSTRAÇÃO DO SUPERÁVIT E DÉFICIT DO EXERCÍCIO (DSDE)}

A Demonstração do Superávit e Déficit do Exercício tem como finalidade exibir de forma sucinta justamente seus déficits e lucros durante cada exercício contábil (OLAK, 2010). Sua nomenclatura parte da Financial Accounting Standards Board (FASB), com base na resolução 117 e equivale à Demonstração do Resultado do Exercício, sustentada pela NBC T 10.19, que solicita trocar os termos lucro e prejuízo para superávit e déficit, pois intenta destacar a finalidade da empresa cuja demonstração foi elaborada. A DFC, por sua vez, é padronizada no Brasil pela Lei № 6.404/76, conhecida como Lei das Sociedades Anônimas, além do CPC 26 (MONTOTO, 2018). É o modelo majoritariamente seguido pelas empresas, apenas incluindo as adaptações terminológicas previstas.

A Demonstração do Resultado, também conhecida por Demonstração de Receitas e Despesas, nas Entidades do Terceiros Setor, são denominadas, normalmente, Demonstração do Superávit ou Déficit do Período. Nas instituições religiosas, as receitas são oriundas das doações, contribuições e dízimos advindos de fiéis e parceiros. As despesas e os custos com serviços são conhecidos pelos gastos para manutenção da instituição. Na Demonstração do Resultado, o lucro ou prejuízo devem ser substituídos por superávit ou déficit. As receitas e as despesas devem ser reconhecidas, mensalmente, respeitando o regime contábil de competência.

Quadro 04 - Demonstrações do Superávit ou do Déficit do Exercício

\section{EMPRESA}

RECEITAS OPERACIONAIS

Dízimos, Ofertas, Doações e Contribuições

(-) DEDUÇÕES DE TRIBUTOS

Despesas Tributárias
$31 / 12 / 20 \times 2$

$31 / 12 / 20 \times 1$

$1.872 .389,37 \quad 2.182 .929,41$

$7.192,11$
$19.360,25$

RC: 100749

Disponível em: https://www.nucleodoconhecimento.com.br/contabilidade/entidades-religiosas 
(-) DESPESAS OPERACIONAIS

Custo do Serviço

Despesas Gerais

$1.293 .690,52 \quad 1.608 .724,46$

Despesas c/Pessoal

$=$ RESULTADO ANTES DO RESULTADO $(35.500,60)$ (227.611,13) FINANCEIRO

(+/-) RESULTADO FINANCEIRO

(-) Despesas Financeiras

$25.853,14$

$3.341,78$

(+) Receitas Financeiras

$11.002,63$

$13.134,75$

= RESULTADO OPERACIONAL ANTES DAS

$(50.351,11)$

$(217.868,16)$

DESPESAS COM TRIBUTOS SOBRE O LUCRO

(-) DESPESA - CSLL E IRPJ

Despesas com Contribuição Social

Despesas com Imposto de Renda Pessoa Jurídica

\section{(=) RESULTADO DO EXERCÍCIO}

\section{Resultado Anual}

$(50.351,11)$

$(217.868,16)$

Fonte: Elaborado pelos autores (2021)

\subsubsection{DEMONSTRAÇÃO DAS MUTAÇÕES DO PATRIMÔNIO LÍQUIDO SOCIAL}

$\mathrm{Na}$ DMPLS, são registradas as movimentações que naturalmente existem no Patrimônio Líquido: PL, reservas, subvenções, ajustes entre exercícios contábeis, 
correções monetárias, seus superávits e déficits. Não são obrigatórias para as entidades de Terceiro Setor, mas são essenciais para a compreensão da movimentação do patrimônio líquido, imprescindíveis, portanto, levando-se em consideração a dependência de muitas instituições dessa natureza quanto às subvenções governamentais (OLAK, 2010). A ITG 2002 indica qual modelo deverá ser utilizado para essa demonstração, essencial para compreender a movimentação do PL (FRANÇA, 2015)

Quadro 05 - Modelo Demonstração das Mutações do Patrimônio Líquido Social

\begin{tabular}{|c|c|c|c|c|c|c|}
\hline \multirow[t]{2}{*}{ Descrição } & \multicolumn{3}{|l|}{ Capital } & \multicolumn{2}{|c|}{ Reserva } & \multirow[t]{2}{*}{ Total } \\
\hline & Subscrito & $\begin{array}{l}\text { A } \\
\text { Realizar }\end{array}$ & Realizado & Capital & Lucros & \\
\hline $\begin{array}{l}\text { Saldo Inicial 31/12 } \\
\text { do Ano Anterior }\end{array}$ & $20.000,00$ & & & & & \\
\hline $\begin{array}{ll}\text { Ajustes } & \text { De } \\
\text { Exercícios } & \\
\text { Anteriores } & \end{array}$ & & & & & & \\
\hline $\begin{array}{l}\text { Aumento De } \\
\text { Capital }\end{array}$ & & $10.000,00$ & & & & \\
\hline $\begin{array}{l}\text { Reversão De } \\
\text { Reservas }\end{array}$ & & & & & & \\
\hline $\begin{array}{l}\text { Lucro Líquido Do } \\
\text { Exercício }\end{array}$ & & & & & & \\
\hline $\begin{array}{l}\text { Destinação De } \\
\text { Lucro }\end{array}$ & & & & & & \\
\hline Reserva & & & & & & \\
\hline Dividendos & & & & & & \\
\hline Saldo Em $31 / 12$ & $30.000,00$ & & & & & $30.000,00$ \\
\hline
\end{tabular}


Do Ano Atual

Fonte: Elaborado pelos autores (2021)

\subsubsection{DEMONSTRAÇÃO DO FLUXO DE CAIXA}

As Demonstrações de Fluxo de Caixa são essenciais para a administração compreender a real situação de seus recursos financeiros, entendendo sua condição de gerar equivalentes de caixa, facilitando a tomada de decisão quanto à sua utilização (RODRIGUES, 2014). A partir da promulgação da Lei № 11.638/07, disposta a atualizar a prática contábil empresarial no Brasil, emparelhando com a contabilidade internacional, algumas demonstrações deixaram de ser obrigatórias para determinadas atividades empresariais. Esse é o caso da DFC para instituições sem fins lucrativos. Apesar de não haver imposição, a DFC é essencial para a operação da instituição como um todo, desde a administração da instituição como, também, para outros usuários envolvidos na condução da entidade (OLAK, 2010).

Quadro 06 - Modelo da Demonstração do Fluxo de Caixa - Instituição religiosa

\begin{tabular}{|l|l|}
\hline Atividade operacional & valores \\
\hline (+) Recebimento de dízimos, ofertas, doações e contribuição & $\mathrm{R} \$ 1.872 .389,37$ \\
\hline (-) Pagamentos de fornecedores & $\mathrm{R} \$ 1.293 .690,52$ \\
\hline (-) Despesas administrativas & $\mathrm{R} \$ 578.698,85$ \\
\hline (=) Caixa operacional obtido & \\
\hline Atividade de investimento & $20.000,00$ \\
\hline (-) Compra de moveis e utensílios & $10.000,00$ \\
\hline (-) Compra de equipamentos & $30.000,00$ \\
\hline (=) Caixa líquido das atividades de investimento & \\
\hline
\end{tabular}

RC: 100749

Disponível em: https://www.nucleodoconhecimento.com.br/contabilidade/entidades-religiosas 
Atividade de financeiro

Entrada de recurso próprio/aumento de capital social

$10.000,00$

Saldo final das disponibilidades

$\mathrm{R} \$ 558.698,85$

Fonte: Elaborado Pelos Autores (2021)

\subsubsection{NOTAS EXPLICATIVAS}

As Notas Explicativas existem para que o elaborador das demonstrações tenha o direito de esclarecer qual seu critério e interpretação dos fatos contábeis documentados, bem como fornecer informações quanto ao contexto operacional da empresa e todos os demais listados no item 27 da ITG 2002 (FRANÇA, 2015). Alguns itens da legislação societária (ITG 2002 e Lei № 6.404/76 sobre S/A) não serão obrigatórios para entidades do Terceiro Setor, mas a NBC T 19.19 explora essas brechas, solicitando, por exemplo, uma breve explicação sobre a natureza da organização e sua não exploração de lucro, doações e subvenções, suas políticas de registro e valores envolvidos nessas contas, situação dos fundos já existentes na instituição e registro de criação de novos, gerando um documento importante para a prestação de contas com aqueles que acreditaram no projeto desenvolvido (OLAK, 2010).

\subsection{BALANÇO SOCIAL}

O Balanço Social, primeiramente utilizado na Alemanha, onde é amplamente empregado, por ser obrigatório para empresas com até trezentos funcionários, é uma ferramenta de cidadania que demonstra o impacto social das entidades, criando uma relação de proximidade e confiança com a sociedade na qual está inserido (TREVISAN, 2002). No Brasil, o balanço social aproveita o que há de bom nas literaturas Norte-Americanas e Europeias. Os modelos mais utilizados são os

RC: 100749

Disponível em: https://www.nucleodoconhecimento.com.br/contabilidade/entidades-religiosas 
divulgados pelo IBASE e Instituto Ethos (LIMA et al., 2021). O Instituto Ethos de Empresas e Responsabilidade Social, referência nacional na divulgação da importância do Balanço Social, possui um manual de elaboração com 30 páginas divulgado gratuitamente para utilização. Descreve cada indicador que deverá ser incluído e sobre como manter a credibilidade da demonstração (ETHOS, 2002), afinal informações abstratas minam a credibilidade e só devem ser consideradas informações quantificáveis.

A professora Roberta Baldo (2002) apresentou em seminário da UMESP (Universidade Metodista de São Paulo) sobre a visão estratégica moderna que é a compreensão quantificada do impacto das Entidades na Sociedade, explorando, nesta fala, sua atuação em setores fragilizados ou setores com impacto direto a sua atividade fim, bem como versou sobre o fortalecimento da marca graças à responsabilidade social, mas, mais importante, é compreender essa responsabilidade social como a atividade fim do Terceiro Setor, já que não é mera questão de marketing social e sim sobrevivência institucional. Entidades sem fins lucrativos precisam da confiança de seus acionistas e doadores. Se o Balanço Social demonstra o impacto da Entidade na sociedade e, por uma questão de transparência, é necessário provar para seus doadores que os objetivos estão sendo cumpridos, torna-se essencial demonstrativos confiáveis desta espécie.

\section{MATERIAIS E MÉTODOS}

Andrade (2010) afirma que a pesquisa bibliográfica é habilidade fundamental nos cursos de graduação, uma vez que constitui o primeiro passo para todas as atividades acadêmicas. Uma pesquisa de laboratório ou de campo implica, necessariamente, a pesquisa bibliográfica preliminar. Seminários, painéis, debates, resumos críticos, monografias não dispensam a pesquisa bibliográfica. Ela é obrigatória nas pesquisas exploratórias, na delimitação do tema de um trabalho ou pesquisa, no desenvolvimento do assunto, nas citações, na apresentação das

RC: 100749

Disponível em: https://www.nucleodoconhecimento.com.br/contabilidade/entidades-religiosas 
conclusões. Portanto, se é verdade que nem todos os alunos realizarão pesquisas de laboratório ou de campo, não é menos verdadeiro que todos, sem exceção, para elaborar os diversos trabalhos solicitados, deverão empreender pesquisas bibliográficas.

\subsection{PROCEDIMENTOS METODOLÓGICOS}

Qualquer pesquisa com pretensão de se tornar científica deve ter uma exposição clara das suas armas - seus métodos de pesquisa. Lakatos e Marconi (2007, p. 80) classificam o conhecimento científico como sistemático e têm sua verificabilidade atestada com base em experiências, não na razão pura. E é exatamente nessa necessidade de verificação que entram os procedimentos metodológicos. O pesquisador expõe como exatamente foi feita sua pesquisa de forma a permitir que pesquisadores posteriores sigam seus passos e testem sua veracidade. Afinal a pesquisa, sendo ordenada, com método devidamente estabelecido e orientado, ou seja, metodológica, perde o caráter subjetivo do senso comum se tornando ciência, esquematizada e sistemática (KOCHE, 2011), pronta para ser utilizada como ponto de partida para outros cientistas que desejam se aprofundar sobre as especificidades do tema.

\subsubsection{QUANTO À NATUREZA}

Segundo Appolinário (2012, p. 62), o interesse da realização da pesquisa básica é estabelecer, de fato, a base para mais pesquisas que virão. Diferentemente da pesquisa aplicada, que se interessa menos na teoria, na compreensão teórica, ou seja, concentra-se mais na aplicação prática, buscando soluções mercadológicas. Não é por outra razão que a pesquisa básica é também conhecida como "Fundamental". Gil (2002, p. 17), por outro lado, crê que essa separação entre natureza de pesquisa básica ou básica-aplicada não cabe na realidade da pesquisa científica, já que um modelo não exclui o outro. Uma pesquisa "puramente" científica

RC: 100749

Disponível em: https://www.nucleodoconhecimento.com.br/contabilidade/entidades-religiosas 
pode solucionar questões práticas. Esta pesquisa se enquadra na pesquisa básica pelo interesse do seu desenvolvimento estar focado em aprofundar o conhecimento a respeito das demonstrações contábeis, da situação tributária das instituições de Terceiro Setor - isenção, legislação - e explicar baseando-se em bibliografias para discutir sobre a importância da transparência e responsabilidade fiscal

\subsubsection{QUANTO AOS FINS}

A pesquisa descritiva é o fim mais buscado por pesquisadores das ciências sociais e objetiva descrever determinado fenômeno focado em um grupo pré-definido por diversos ângulos, coletando informação sem interferir no resultado (GIL, 2002). Gil aprofunda esclarecendo que essa modalidade foca no "quê" e em "como" acontecem esses eventos ao invés do "porquê", que é o objetivo da pesquisa explicativa. Ao iniciar a pesquisa, é importante definir hipóteses, ainda que, segundo Lakatos e Marconi (2007, p. 161), não seja obrigatório as desenvolver formalmente durante a pesquisa descritiva. A pesquisa enfoca na bibliografia, mostrando, nesse caso, as demonstrações contábeis, facilitando a compreensão de sua importância junto ao Terceiro Setor, aproveitando o material coletado sem fazer inflexões quanto ao seu resultado final.

\subsubsection{QUANTO AOS MEIOS}

Foi realizada uma pesquisa de caráter bibliográfico, caracterizada por Severino (2017, p. 93) como estudo realizado por meio da pesquisa do material disponível, seja na forma de artigos, livros, teses. Kleina e Rodrigues (2014) afirmam que é de caráter obrigatório detalhar os passos da pesquisa bibliográfica, ainda que constitua capítulo específico para definir metodologia, podendo limitar-se a um parágrafo, descrito na introdução. Quanto à pesquisa documental, Severino (2017) a define como um método de pesquisa mais amplo, englobando outras espécies de impressos, sobretudo outros tipos de documentos como, jornais, fotografias e

RC: 100749

Disponível em: https://www.nucleodoconhecimento.com.br/contabilidade/entidades-religiosas 
documentos legais, além da legislação vigente. Sendo assim, um material relativamente bruto e não tão analisado, comparado à pesquisa bibliográfica. Esta pesquisa é ao mesmo tempo bibliográfica e documental, pois, além da literatura exigente, aprofundou-se um pouco em legislações, pronunciamentos contábeis e matérias jornalísticas, como conduziu a própria pesquisa.

\section{CONSIDERAÇÕES FINAIS}

Com o presente estudo, evidenciou-se a resposta da questão norteadora: De que maneira as demonstrações contábeis podem trazer credibilidade às entidades religiosas? verificou-se que seu uso é imprescindível na gestão, visto que os demonstrativos gerados pela contabilidade possuem uma enorme quantidade de informações que podem direcionar os administradores e gestores a tomada de decisões mais eficientes e eficazes, apresentando, assim, maior credibilidade a essas entidades. Quanto ao objetivo deste estudo, buscou-se demonstrar a transparência das demonstrações contábeis, das receitas advindas de doações, parcerias, ofertas, dízimos e patrocínios, assim como das despesas geradas. Notouse que as demonstrações contábeis são essenciais, tanto para as entidades religiosas quanto para a sociedade em geral, uma vez que, no Brasil, uma grande maioria da população é praticante de alguma atividade religiosa e tem o anseio de saber onde suas doações estão sendo aplicadas.

As entidades, por sua vez, possuem carência de informações precisas acerca de como contabilizar seus recursos e trazer essas informações para as partes interessadas. Em relação à hipótese apresentada no estudo, o fato de o Terceiro Setor, no Brasil, possuir diversas particularidades em suas demonstrações contábeis, a probabilidade de erros cresce, visto que a falta de profissionais qualificados na área ainda é um problema em nosso país. Tais erros podem causar grande descontrole na área financeira e administrativa da instituição e pode-se gerar em seus doadores a dúvida quanto à aplicação de suas doações, fato que

RC: 100749

Disponível em: https://www.nucleodoconhecimento.com.br/contabilidade/entidades-religiosas 
pode ser fatal à entidade. Demonstrar essas informações de forma clara e precisa é imprescindível à sobrevivência da instituição.

Por fim, espera-se que este trabalho possa fomentar o debate sobre o tema e, assim, contribuir com o aperfeiçoamento do processo de demonstrações e prestação de contas das organizações que compõem o Terceiro Setor no Brasil, também conhecidas como Entidades Sem Fins Lucrativos, aumentando a sua credibilidade e crescimento.

\section{REFERÊNCIAS}

ALMEIDA, V. E. de.; ESPEJO, R. A. Contabilidade no Terceiro Setor. $1^{a}$ ed. Curitiba, PR: IESDE Brasil S.A, 2012.

ANDRADE, M. G. V. de. Organizações do terceiro setor: estratégias para captação de recursos junto às empresas privadas. 2002. 146f. Dissertação (Mestrado em Engenharia de Produção) - Universidade Federal de Santa Catarina, Florianópolis, SC, 2002.

APPOLINÁRIO, F. Metodologia da ciência: filosofia e prática de pesquisa. $2^{\underline{a}}$ ed. São Paulo: Cengage Learning, 2011.

ARAÚJO, O. C. Contabilidade para Organizações do Terceiro Setor. $1^{\underline{a}}$ ed. São Paulo: Atlas, 2009.

BALDO, R. A empresa cidadã frente ao Balanço Social. In: INTERCOM - Sociedade Brasileira de Estudos Interdisciplinares da Comunicação XXV Congresso Brasileiro de Ciências da Comunicação, 2002.

BARBIERI, C. B. Terceiro Setor - desafios e perspectivas constitucionais. Curitiba: Juruá Editora, 2008. 
BRASIL. Código Civil Brasileiro. Disponível em: http://www.planalto.gov.br/ccivil_03/leis/2002/10406.htm. Acesso em: 08 ago. 2021.

BRASIL. Constituição Federativa do Brasil de 1988. Disponível em: http://www.planalto.gov.br/ccivil_03/constituicao/Constituicao.htm. Acessado em: 08 ago. 2021.

BRITO, H. de.; SEGUNDO, M. Manual de direito tributário. $10^{\mathrm{a}}$ ed. rev. atual. e. ampl. São Paulo: Atlas, 2018.

CÂMARA, S.; KESSLER, N. Administração eclesiástica. 20aㅡ ed. Rio de Janeiro: CPAD, 2012.

CARDOSO, U. C. OSCIP: organização da sociedade civil de interesse público. Brasília: Sebrae, 2014.

COELHO, S. de. C. T. Terceiro Setor: um estudo comparado entre Brasil e Estados Unidos. $2^{\mathrm{a}}$ ed. São Paulo: Editora SENAC São Paulo, 2002.

$\mathrm{CRC/RS} \mathrm{-} \mathrm{Terceiro} \mathrm{Setor:} \mathrm{guia} \mathrm{de} \mathrm{orientação} \mathrm{para} \mathrm{o} \mathrm{profissional} \mathrm{da}$ Contabilidade. $3^{a}$ ed. Porto Alegre: Edição Exclusivamente Eletrônica, 2018.

FRANÇA, J. A. de. Manual de Procedimentos para o Terceiro Setor: aspectos de gestão e de contabilidade para entidades de interesse social. Brasília: CFC: PROFIS, 2015.

GIL, A. C. Como elaborar projetos de pesquisa. $4^{a}$ ed. São Paulo: Atlas, 2002.

KLEINA, C.; RODRIGUES, K. S. B. Metodologia de pesquisa e trabalho científico. $1^{\text {a }}$ ed. Curitiba: IESDE BRASIL S/A, 2014. 
KOCHE, J. C. Fundamentos da metodologia científica. Rio de Janeiro: Editora Vozes, 2011.

LAKATOS, E. M.; MARCONI, M. de. A. Metodologia do trabalho científico. $5^{\mathrm{a}}$ ed. São Paulo: Atlas, 2003.

LAKATOS, E. M.; MARCONI, M. de. A. Fundamentos de metodologia científica: técnicas de pesquisa. $7^{a}$ ed. São Paulo: Atlas, 2010.

LIMA, E. O.; STETTINER, C. F.; FERREIRA JR, S. Balanço social e o "full disclosure" no terceiro setor. Revista de Tecnologia Aplicada, v. 10, n. 1, p. 23-39, 2021.

MONELLO, S. R. Organizações Religiosas e o Código Civil Brasileiro. [Entre 2010 e 2017b]. Disponível em: www.advocaciasergiomonello.com.br/.../16asorganizacoes-religiosas-e-o-codigo-civ.... Acesso em: 08 ago. 2021.

MONTEIRO, J. R. M. Captação de Recursos no Terceiro Setor. Portal Educação, 2011. Disponível em:

https://www.portaleducacao.com.br/conteudo/artigos/contabilidade/captacao-derecursos-no-terceiro-setor/10378. Acesso em: 11 set. 2021.

MONTOTO, E. Contabilidade geral e avançada esquematizado. $5^{\underline{a}}$ ed. São Paulo: Saraiva Educação, 2018.

NASCIMENTO JUNIOR, D. L. do. Como registrar as despesas corretamente nas Organizações Religiosas. Contábeis, 2019. Disponível em: https://www.contabeis.com.br/artigos/5279/como-registrar-as-despesascorretamente-nas-organizacoes-religiosas/. Acesso em: 02 nov. 2021.

OLAK, P. A.; NASCIMENTO, D. T. do. Contabilidade para entidades sem fins lucrativos (terceiro setor). 3를. ed. São Paulo: Atlas, 2010.

RC: 100749

Disponível em: https://www.nucleodoconhecimento.com.br/contabilidade/entidades-religiosas 
OLIVEIRA, A.; ROMÃO, V. Manual do Terceiro Setor e instituições religiosas: trabalhistas, previdenciária, contábil e fiscal. São Paulo: Atlas. 2011

PADOVEZE, C. L. Análise das demonstrações financeiras. $3^{\underline{a}}$ ed. rev. e ampl. São Paulo: Cengage Learning, 2010.

PAES, J. E. S. Fundações, associações e entidades de interesse social: aspectos jurídicos, administrativos, contábeis, trabalhistas e tributários. $7^{\underline{a}}$ ed. São Paulo: Forense, 2010.

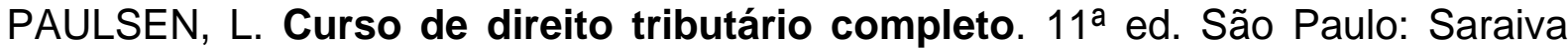
Educação, 2020.

PÊGAS, P. H. Manual de contabilidade tributária. $9^{\underline{a}}$ ed. $3^{\text {a }}$ reimp. São Paulo: Atlas, 2019.

RODRIGUES, A. Contabilidade empresarial: textos e casos sobre CPC e IFRS. $1^{\text {a }}$ ed. Rio de Janeiro: Elsevier, 2014.

RODRIGUES, A. Contabilidade do 3 setor (organizações não governamentais, entidades beneficentes e entidades sem fins lucrativos). $2^{\text {a }}$ ed. São Paulo: IOB, 2010 .

SANTOS, L. B. dos. et al. Governança nas organizações religiosas: relato de uma pesquisa. RAGC -Revista de Auditoria Governança e Contabilidade, v. 7, n. 31, p. 35-59, 2019.

SEVERINO, A. J. Metodologia do trabalho científico. 24를 ed. São Paulo: Cortez, 2017

SOUZA, L. M. de. Tributação do Terceiro Setor no Brasil. São Paulo: Dialética, 2004

RC: 100749

Disponível em: https://www.nucleodoconhecimento.com.br/contabilidade/entidades-religiosas 
TREVISAN, F. A. Balanço social como instrumento de marketing. RAE eletrônica, v. 1, n. 2, p. 1-12, 2002.

Enviado: Outubro, 2021.

Aprovado: Novembro, 2021. 